1 Savage COS, Winearls CG, Evans DJ, Rees AJ, Lockwood CM. Microscopic polyarteritis. Presentation, pathology and prognosis. $Q J$ Med 1985;56:467-84

2 Leatherman JW, Davies SF, Hoidal JR. Alveolar haemorrhage syndromes: diffuse microvascular lung haemorrhage in immune and idiopathic disorders. Medicine 1984;63: 343-61.

3 Corrin B, Jagusch M, Dewar A, et al. Fine structural changes in idiopathic pulmonary haemosiderosis. J Pathol 1987; 153:249-56.

4 Falk RJ, Jennette CJ. ANCA with specificity for myeloperoxidase in patients with systemic vasculitis and idiopathic necrotizing and crescentic glomerulonephritis. idiopathic necrotizing and crescent

5 Tervaert JWC, Goldschmeding R, Elema JD, Limburg PC, van der Giessen M, Hitema MG, et al. Association of autoantibodies to myeloperoxidase with different forms of vasculitis. Arth Rheum 1990;33:1264-72.

6 Jennette JC, Falk RJ. Antineutrophil cytoplasmic auto- antibodies and associated diseases: a review. Am J Kidney Dis 1990;15:517-29.

7 Niles JL, Pan G, Collins B, Shannon T, Skates S, Fienberg $\mathrm{R}$, et al. Antigen-specific radioimmunoassays for antineutrophil cytoplasmic antibodies in the diagnosis of rapidly progressive glomerulonephritis. J Am Soc Nephrol 1991;2:27-36.

$8 \mathrm{Nada}$ AK, Torres VE. Pulmonary fibrosis as an unusual manifestation of a pulmonary-renal vasculitis in elderly patients. Mayo Clin Proc 1990;65:847-56.

9 Jayne DRW, Jones SJ, Severn A, Shaunak S, Murphy J, Lockwood CM. Severe pulmonary haemorrhage and systemic vasculitis in association with circulating antineutrophil cytoplasm antibodies of IgM class only. Clin Nephrol 1989;32:101-6.

10 Fauci AS, Barton F, Haynes MD, Katz P, Wolff SM. Wegener's granulomatosis: prospective clinical and therapeutic experience with 85 patients for 21 years. $A n n$ Intern Med 1983;98:76-85.

\section{Extrinsic allergic alveolitis caused by goose feathers in a duvet}

\author{
Tj Haitjema, $H$ van Velzen-Blad, \\ $\mathrm{J} M \mathrm{M}$ van den Bosch
}

\section{Department of Pulmonology Tj Haitjema J M M van den Bosch \\ Department of Medical Microbiology and Immunology $H$ van Velzen-Blad \\ St Antonius Hospital, Koekoekslaan 1, 3435 CM Nieuwegein, The Netherlands \\ Reprint requests to: Dr MM van den Bosch Received 27 January 1992 Returned to authors 22 April 1992 Revised version received 4 June 1992 \\ Accepted 16 June 1992}

\begin{abstract}
A patient with extrinsic allergic alveolitis had precipitating antibodies to many avian antigens. A duvet containing goose feathers proved to be the source of antigenic material.
\end{abstract}

\section{(Thorax 1992;47:990-991)}

Extrinsic allergic alveolitis is a well known disease caused by inhalation of organic dusts or of inorganic chemicals, leading to bronchoalveolar inflammation. Birds are a common cause and reactions to antigens from pigeons, budgerigars, hens, parrots, canaries, and turkeys have been reported. We describe a case of extrinsic allergic alveolitis caused by goose feathers in a duvet.

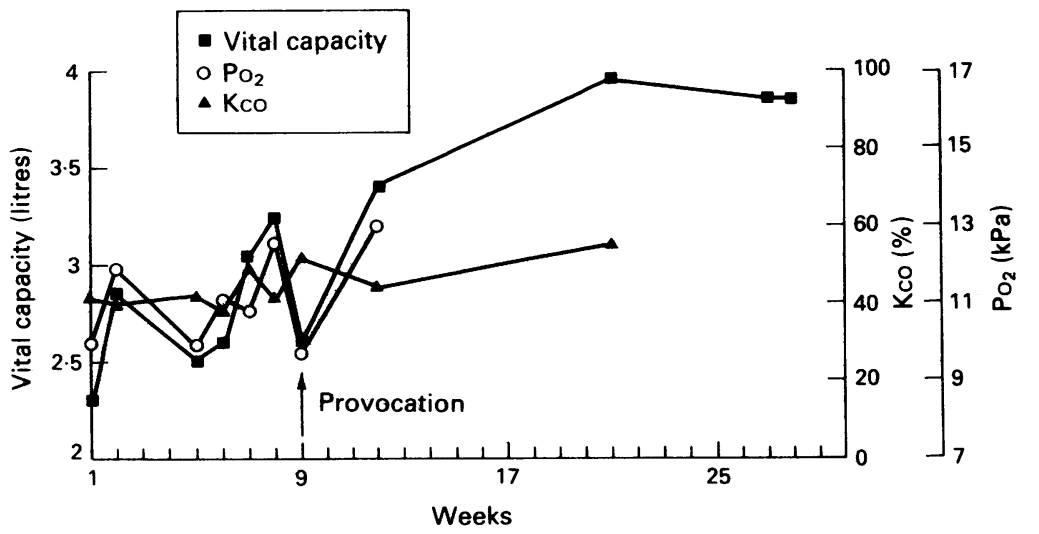

Results of lung function tests.

\section{Case report}

A 31 year old, previously healthy, non-smoking woman was admitted to hospital with increasing shortness of breath, purulent sputum, and fever. Her complaints had started three weeks previously and had not been improved by erythromycin. She had lost $4 \mathrm{~kg}$. She had no previous history of allergy, occupational exposure to organic or inorganic dusts, or respiratory tract infection. She kept a cat.

A chest radiograph showed a reticulonodular pattern, predominantly in the lower zone. Her erythrocyte sedimentation rate was $29 \mathrm{~mm}$ in the first hour (normal $<10 \mathrm{~mm}$ ); angiotensin converting enzyme activity was 85 (normal $<50)$ IU. No other biochemical values were abnormal. Lung function tests showed a vital capacity of 2.3 (normal 3.93) 1 , an $\mathrm{FEV}_{1}$ of 1.71 , a gas transfer coefficient (KCo) of $41 \%$, and hypoxaemia worsening during exercise (arterial oxygen tension $10.0 \mathrm{kPa}$ at rest, $7.5 \mathrm{kPa}$ after cycle ergometer testing with a work load of $13 \cdot 2 \mathrm{~kJ}$ ). Specific lung compliance was reduced to 0.28 (expected $0.7-1 \cdot 1$ ) $\mathrm{kPa}^{-1}$. Bronchoalveolar lavage was performed on day 2, which showed lymphocytosis, with an increased number of $T$ lymphocytes, and a low CD4:CD8 ratio (table). The immunoglobulin: albumin ratios in the lavage fluid supernatant, including IgM:albumin, were increased. These results were consistent with extrinsic allergic alveolitis; a detailed history, however, indicated no possible antigen.

The patient improved spontaneously in hospital, becoming afebrile after seven days, and improvements were seen in the measurements made from a second bronchoalveolar lavage, performed after nine days in hospital (table). She was discharged, and went to stay with her parents, where she continued to improve (figure). Tests for precipitating antibodies against pigeon, budgerigar, canary, and parrot antigens then proved to be positive. A renewed search of the patient's home revealed only a duvet and a pillow, containing nothing but goose feathers (confirmed by the manufacturer) as a possible source of antigenic material. The patient had used the duvet for four years. Retrospectively, the precipitating antibodies against goose antigens proved to be strongly 
Results of bronchoalveolar lavage on day 2, day 9, and after provocation with the duvet

\begin{tabular}{|c|c|c|c|}
\hline & Day 2 & Day 9 & $\begin{array}{l}10 \text { hours } \\
\text { after } \\
\text { provocation }\end{array}$ \\
\hline Number of cells $\left(\times 10^{6}\right)$ & $66 \cdot 4$ & $25 \cdot 2$ & $34 \cdot 4$ \\
\hline \multicolumn{4}{|l|}{ Cell types $(\%)$} \\
\hline macrophages & $24 \cdot 5$ & $46 \cdot 4$ & 43.9 \\
\hline lymphocytes & $70 \cdot 0$ & $47 \cdot 7$ & $20 \cdot 6$ \\
\hline neutrophils & $2 \cdot 6$ & $2 \cdot 0$ & $28 \cdot 5$ \\
\hline eosinophils & $2 \cdot 6$ & $2 \cdot 7$ & $6 \cdot 4$ \\
\hline basophils & 0.0 & $0 \cdot 8$ & 0.6 \\
\hline plasma cells & 0.3 & 0.4 & 0.0 \\
\hline T lymphocytes ${ }^{\star}$ & 91 & 86 & 80 \\
\hline $\mathrm{CD} 4: \mathrm{CD} 8$ & 0.7 & 0.3 & 0.4 \\
\hline IgM ratio $\dagger$ & $1 \cdot 1$ & $1 \cdot 3$ & $0 \cdot 6$ \\
\hline IgG ratio & $2 \cdot 0$ & $2 \cdot 1$ & $1 \cdot 3$ \\
\hline IgA ratio & $1 \cdot 4$ & $2 \cdot 3$ & $1 \cdot 2$ \\
\hline
\end{tabular}

«Expressed as percentage of all lymphocytes.

$+(\text { Ig/albumin })_{\text {lavage supernatant }}$ (Ig/albumin $)_{\text {serum }}$.

positive. Six weeks after discharge our patient was asked to sleep for one night under her duvet using her own pillow. After six hours she complained of shortness of breath and cough, and had a temperature of $39 \cdot 1^{\circ} \mathrm{C}$. Bronchoalveolar lavage, performed 10 hours after the start of the provocation, showed neutrophilia (table), compatible with an acute form of extrinsic allergic alveolitis. The patient returned home without her duvet and pillow, and remained free of symptoms. Since then lung function values have slowly improved (figure) and arterial blood gases have become normal; tests for precipitating antibodies to goose antigens still give strongly positive results but the precipitating antibodies to other avian antigens have decreased.

\section{Discussion}

In 1960 Plessner $^{1}$ described a reaction occurring in feather pluckers, when they were handling feathers from ducks and geese. The reaction consisted of fatigue, fever, nausea, dyspnoea, and cough. These symptoms started three to four hours after exposure, and gradually disappeared after exposure had ceased. Fitting and Leuenberger ${ }^{2}$ described a patient with a condition similar to extrinsic allergic alveolitis, with a lavage fluid profile consistent with extrinsic allergic alveolitis, whose reaction was also attributed to a duvet containing goose feathers. But because no precipitating antibodies to avian antigens were identified, the alveolitis in their patient was based on a non-immunological reaction to components of the duvet, rather than to extrinsic allergic alveolitis caused by goose feathers. ${ }^{2}$

We believe that our patient developed extrinsic allergic alveolitis caused by goose feather antigens because of the clinical picture, the patient's symptoms, the laboratory results, and the lung function and radiographic findings. The temporal relation between provocation and the start of the symptoms suggested a type III allergic reaction. A positive reaction to the provocation test with the duvet and disappearance of the complaints after removal of the duvet from the patient's home confirm an aetiological role of the goose feathers.

We found precipitating antibodies against goose antigens as well as against other bird antigens; the antibody titres against the latter decreased after discontinuation of contact with the duvet. We believe the goose antibodies to be cross reacting with other avian antigens, as has been described previously. ${ }^{34}$

The lavage results at presentation, as well as after provocation, are consistent with extrinsic allergic alveolitis. Lymphocytosis with an increased proportion of $\mathrm{T}$ lymphocytes showing a low CD4:CD8 ratio, the increased amount of immunoglobulin in the lavage supernatant, and neutrophilia after provocation support this diagnosis. ${ }^{5-8}$ According to previous findings ${ }^{9}$ and our own unpublished data the presence of plasma cells in lavage fluid suggests a diagnosis of extrinsic allergic alveolitis.

In view of the fact that duvets are becoming increasingly popular, physicians should be aware of this possible source of antigenic material when investigating patients with suspected extrinsic allergic alveolitis. This case further suggests that extrinsic allergic alveolitis is not always caused by live birds, but can be caused by feathers alone.

1 Plessner MM. Une maladie des trieurs de plumes: la fièvre du canard. Arch Mal Prof 1960;21:67-9.

2 Fitting JW, Leuenberger PH. Augmentation des polynucleaires neutrophiles du liquide de lavage bronchoalveolaire apres exposition dans un cas d'alveolite aigue. Rev Mal Respir 1984; i:301-4.

3 Andersen $P$, Schonheyder $H$. Antibodies to hen and duck antigens in poultry workers. Clin allergy 1984;14:421-8.

4 Faux JA, Wells ID, Pepys J. Specificity of avian serum proteins in tests against the sera of bird fanciers. Clin proteins in tests against

5 Costabel U, Bross KJ, Marxen J, Matthys H. T-lymphocytosis in bronchoalveolar lavage fluid of hypersensitivity pneumonitis. Chest 1984;85:514-8.

6 Daniele RP, Elias JA, Epstein PE, Rossman MD. Bronchoalveolar lavage: role in the pathogenesis, diagnosis, and management of interstitial lung disease. Ann Intern Med management of in

7 Rust M, Schultze-Werninghaus G, Meier-Sydow J. Bronchoalveolar lavage as a tool to assess an inhalative provocation in extrinsic allergic alveolitis. Prax Klin Pneumo 1986;40:229-32.

8 van den Bosch JMM, Heye C, Wagenaar SjSc, van VelzenBlad HCW. Bronchoalveolar lavage in extrinsic allergic alveolitis. Respiration 1986;49:45-51.

9 Costabel U, Bross KJ, Guzman J, Matthys H. Plasmazellen und lymphozytensubpopulationen in der bronchoalveolären lavage bei exogen-allergischer Alveolitis. Prax Klin Pneumol 1985;39:925-6. 